\title{
Getting a Job: Is There a Motherhood Penalty? ${ }^{1}$
}

\author{
Shelley J. Correll, Stephen Benard, and In Paik \\ Cornell University
}

\begin{abstract}
Survey research finds that mothers suffer a substantial wage penalty, although the causal mechanism producing it remains elusive. The authors employed a laboratory experiment to evaluate the hypothesis that status-based discrimination plays an important role and an audit study of actual employers to assess its real-world implications. In both studies, participants evaluated application materials for a pair of same-gender equally qualified job candidates who differed on parental status. The laboratory experiment found that mothers were penalized on a host of measures, including perceived competence and recommended starting salary. Men were not penalized for, and sometimes benefited from, being a parent. The audit study showed that actual employers discriminate against mothers, but not against fathers.
\end{abstract}

Mothers experience disadvantages in the workplace in addition to those commonly associated with gender. For example, two recent studies find that employed mothers in the United States suffer a per-child wage penalty of approximately $5 \%$, on average, after controlling for the usual human capital and occupational factors that affect wages (Budig and England 2001; Anderson, Binder, and Krause 2003). In a summary of economic research, Crittenden (2001) concludes that, for those under the age of 35, the pay gap between mothers and nonmothers is larger than the pay gap between men and women. As Glass (2004) notes, employed mothers are

\footnotetext{
${ }^{1}$ We thank Pi-Chun Hsu, Devah Pager, Cecilia Ridgeway, Cate Taylor, Lisa Troyer, Kim Weeden, and Robb Willer for helpful comments and suggestions, and Maysha Artis, Monica Celedon, Heather Ferguson, Adrienne Gallet, Kim Gillece, Kathryn Heley, Shari Moseley, Shana Platz, Connor Puleo, Kristin Seeger, and Michael Stein for capable research assistance. Support for this research was provided by a grant to the first author from the Alfred P. Sloan Foundation. Direct correspondence to Shelley J. Correll, Department of Sociology, 323 Uris Hall, Cornell University, Ithaca, New York 14853. E-mail: sjc62@cornell.edu
}

(C) 2007 by The University of Chicago. All rights reserved. 0002-9602/2007/11205-0001\$10.00

AJS Volume 112 Number 5 (March 2007): 1297-1338 
American Journal of Sociology

the group of women that now account for most of the "gender gap" in wages.

The disadvantages are not limited to pay. Cuddy, Fiske, and Glick (2004) show that describing a consultant as a mother leads evaluators to rate her as less competent than when she is described as not having children. Similarly, other studies show that visibly pregnant women managers are judged as less committed to their jobs, less dependable, and less authoritative, but warmer, more emotional, and more irrational than otherwise equal women managers who are not visibly pregnant (Halpert, Wilson, and Hickman 1993; Corse 1990). While the pattern is clear, the underlying mechanism remains opaque. Why would being a parent lead to disadvantages in the workplace for women? And why might similar disadvantages not occur for men?

This article presents a laboratory experiment and an audit study of actual employers. The laboratory experiment evaluates the hypothesis that the "motherhood penalty" on wages and evaluations of workplace performance and suitability occurs, at least partially, because cultural understandings of the motherhood role exist in tension with the cultural understandings of the "ideal worker" role. We propose that this perceived tension between incompatible cultural understandings or schemas leads evaluators, perhaps unconsciously, to expect mothers to be less competent and less committed to their jobs (Blair-Loy 2003; Ridgeway and Correll 2004). To the extent that mothers are believed to be less committed to the workplace, we argue that employers will subtly discriminate against mothers when making evaluations that affect hiring, promotion, and salary decisions. We do not expect that fathers will experience these types of workplace disadvantages since understandings of what it means to be a good father are not seen in our culture as incompatible with understandings of what it means to be a good worker (Townsend 2002). By having participants rate job applicants, we expect that applicants presented as women with children will be viewed as less competent and less committed to work, will need to present evidence that they are more qualified for the job, will be rated as less promotable, and will be offered lower starting salaries compared with otherwise similar applicants presented as women without children. We also expect that the motherhood penalty will be mediated by evaluations of competence and commitment. While the laboratory experiment allows us to isolate and examine the mechanism of discrimination, the audit study provides external validity by evaluating whether actual employers discriminate against mothers.

In the following paragraphs we review the empirical literature on the motherhood wage penalty and existing explanations for it. We then develop our theoretical argument by drawing on status characteristics theory and the literature on cultural conceptions of motherhood. Finally, we 
describe the laboratory experiment and the audit study, and summarize evidence for the motherhood penalty from these two studies.

\section{WAGE PENALTY FOR MOTHERHOOD}

A variety of factors have been proposed as explanations for the motherhood wage gap, including reduced investment in human capital by mothers, lower work effort by mothers compared with nonmothers, unobserved heterogeneity between mothers and nonmothers, and discrimination against mothers by employers. In general, explanations for the motherhood wage penalty can be classified as those that seek to identify important differences in the traits, skills, and behaviors between mothers and nonmothers (i.e., worker explanations) and those that rely on the differential preference for or treatment of mothers and nonmothers (i.e., discrimination explanations). Empirical evaluations of these explanations have largely focused on the former.

For example, Budig and England (2001) examine differences in work patterns between mothers and nonmothers and find that interruptions from work, working part-time, and decreased seniority/experience collectively explain no more than about one-third of the motherhood penalty. They also show that "mother-friendly" job characteristics (i.e., differences in the type of jobs mothers and nonmothers choose) explain very little of the penalty. Similarly, Anderson et al. (2003) find that human capital, occupational, and household resource variables (e.g., number of adults in the household) collectively account for $24 \%$ of the total wage penalty for one child and $44 \%$ for women with two or more children. Likewise, Waldfogel and Meyer (2000) find that occupational controls do not eliminate the penalty. As Budig and England (2001) conclude, the remaining wage gap likely arises either because employed mothers are somehow less productive at work than nonmothers or because employers discriminate against mothers (or some combination of the two processes).

Becker's (1985) "work effort" hypothesis is perhaps the best-known productivity explanation. According to Becker, mothers may in fact be less productive at work because they have dissipated their reserve of energy caring for their children. In an indirect attempt to evaluate this claim, Anderson et al. (2003) compare the motherhood wage penalty for mothers in different educational groups-high school dropouts, high school graduates, those with some college, and college graduates. They hypothesize that if jobs that require more education require more effort, then the motherhood wage penalty should be greater for mothers with higher levels of education. Contrary to this prediction, Anderson and colleagues found that mothers who were high school graduates actually 


\section{American Journal of Sociology}

experienced the largest wage penalty. They interpret this nonmonotonic relationship between level of education and the magnitude of the wage penalty as evidence contradicting productivity explanations of the motherhood wage penalty. However, the authors lack direct measures of productivity, limiting their ability to rule out productivity explanations.

Productivity and Discrimination

A logical way to distinguish between discrimination and productivity explanations would be to compare the workplace outcomes (e.g., salaries, hiring, promotions) of employed mothers and nonmothers who have equal levels of workplace productivity. If differences in pay or promotion rates were found between groups of mothers and nonmothers whose productivity levels were equal, this finding would suggest that discrimination factors were at work. However, the data sets analyzed in the studies described above lack direct measures of worker productivity. One likely reason for the lack of workplace productivity measures is that it is inherently problematic to fully specify what makes someone a good or productive employee. This difficulty leads to another: unexplained gaps in wages between two groups (e.g., employed mothers and nonmothers) can always be attributed to unmeasured productivity differences between the two groups. For example, if the wages of attorneys were compared and productivity was measured in terms of billable hours, and it was found that controlling for this measure of productivity, female attorneys with children earned less than female attorneys without children, we could not know whether the wage gap found was the result of discrimination against employed mothers or was instead the result of some other unmeasured form of productivity.

To address these problems, in both the laboratory and audit studies, we experimentally hold constant the workplace performances and other relevant characteristics of a pair of fictitious job applicants and vary only their parental status. In the laboratory experiment, we measure how evaluators rate the applicants in terms of perceived competence, workplace commitment, hireability, promotability, and recommended salary. In the audit study, we measure positive responses to applicants based on the number of callbacks from actual employers. By experimentally holding constant workplace-relevant characteristics of the applicants, any differences between the ratings of mothers and nonmothers cannot be attributed to productivity or skill differences. While this design cannot rule out the possibility that productivity differences account for part of the wage penalty that has been shown to exist, the laboratory study will isolate a potential status-based discrimination mechanism by evaluating whether being a parent disadvantages mothers in the workplace even when no 
productivity differences exist between them and women without children. In the next section, we draw on status characteristics theory to develop an explanation for how motherhood status could lead to evaluative biases against employed mothers.

\section{PERFORMANCE EXPECTATIONS AND EVALUATIONS OF WORKPLACE COMPETENCE}

\section{Status Characteristics Theory}

The theoretical claim to be advanced and evaluated is that motherhood is a "status characteristic" that, when salient, results in biased evaluations of competence and commitment, the use of a stricter standard for evaluating the workplace performances of mothers than of nonmothers, and a bias against mothers in hiring, promotion, and salary decisions. As defined by status characteristics theory, a status characteristic is a categorical distinction among people such as a personal attribute (e.g., race, gender) or a role (e.g., motherhood, manager), that has attached to it widely held beliefs in the culture that associate greater status worthiness and competence with one category of the distinction than with others (Berger et al. 1977). A status characteristic becomes salient when it differentiates those in the setting or because the characteristic is believed to be directly relevant to the task at hand. The theory argues that actors then implicitly use the salient characteristic to guide their behaviors and evaluations.

The theoretical construct linking status characteristics, such as gender or race, to differences in behaviors and evaluations is "performance expectations." According to the theory, actors implicitly expect more competent task performances from those with the more valued state of a characteristic (men, managers) compared with those with the less valued state (women, nonmanagers). These differentiated performance expectations operate in a self-fulfilling way-since they are expected to offer more competent performances, high-status actors are given more opportunities to participate, have more influence over others in a group, and, importantly for the current project, have their performances evaluated more positively (see Correll and Ridgeway 2003). These effects are predicted except when the task or setting is one for which lower-status individuals are believed to be "naturally" better, such as a task requiring nurturing ability in the case of gender. Experiments confirm that a wide variety of status characteristics, including race, gender, level of education, and physical attractiveness, systematically organize the appearance of competence, influence, and deference in this manner (Lovaglia et al. 1998; Ridgeway 2001; Troyer and Younts 1997; Webster and Foschi 1988).

Theory and empirical research suggest that in addition to their impact 


\section{American Journal of Sociology}

on performance evaluations, status characteristics also affect the standard individuals use to determine whether a given performance is indicative of ability (Foschi 1989). The central idea is that ability standards are stricter for those with lower performance expectations, that is, those with devalued status characteristics. The logic behind this prediction is that good performances are inconsistent with expectations for lower-status actors; therefore when lower-status actors perform well at a task, their performances are critically scrutinized. When higher-status actors perform equally as well, their performances are consistent with expectations and are therefore less scrutinized. Since performances of lower-status actors are more heavily scrutinized, their performances are judged by a stricter standard compared with higher-status actors. Therefore, the performances of low-status actors-even when "objectively" equal to that of their highstatus counterparts-are less likely to be judged as demonstrating task ability or competence. A "double standard" benefiting high-status individuals is predicted except when the task or setting is culturally associated with the low-status group (e.g., a task requiring nurturing ability might advantage mothers over childless employees). Empirical evidence supports these predictions for both gender and race, and the predictions hold both when individuals evaluate others and when they evaluate themselves (Foschi 1996; Biernat and Kobrynowicz 1997; Correll 2001, 2004).

If motherhood is a devalued status in workplace settings, we predict that mothers will be judged by a harsher standard than nonmothers. They will have to present evidence of greater ability before being seen as competent. While this argument shares some similarities with economic theories of statistical discrimination (Phelps 1972; Arrow 1973; Bielby and Baron 1986), status-based discrimination differs in that it claims that the standard used to evaluate workers is systematically biased in favor of high-status groups. ${ }^{2}$

${ }^{2}$ In its original formulation, the theory of statistical discrimination assumes that one group of people (e.g., African-Americans, women, or mothers) are less productive than another group (e.g., whites, men, nonmothers), and that obtaining information about the productivity of individuals is prohibitively expensive (Phelps 1972). Rational employers therefore prefer to hire workers from the more productive group. While theories of statistical discrimination assume that employers apply an unbiased standard to accurate estimates of worker productivity, theories of status-based discrimination argue that the standard of evaluation is systematically biased in favor of the high-status group. Furthermore, statistical discrimination theories assume rational actors relying on biased information, while status theories assume that cultural beliefs distort cognition, even when information is perfect. These differences appear subtle, but lead to differing predictions. Consider the hypothetical case of two equally productive employees, a father and a mother, who have each left work early twice within the last month. Statistical discrimination theories predict no differences by gender when a supervisor evaluates the two employees. Status theories, in contrast, predict that the mother will be held to a harsher standard. For example, a supervisor may assume 
Motherhood Penalty

Preliminary Empirical Support

Recent studies provide some evidence consistent with status-based discrimination and illustrate that the disadvantages associated with motherhood are not limited to pay. In one experiment, participants were asked to imagine that they were clients choosing a consultant from a consulting firm (Cuddy et al. 2004). The researchers found that simply adding the phrase "has a two-year-old child" to the description of the consultant lead evaluators to rate the consultant as less competent than an otherwise equal consultant not presented as having a child. Likewise, Fuegen et al. (2004) found that when evaluators rated fictitious applicants for an attorney position, female applicants with children were held to a slightly, although insignificantly, higher standard than female applicants without children. Fathers were actually held to a significantly lower standard than male nonparents.

Not all the results in these two studies were consistent with the authors' empirical predictions. For example, Cuddy et al. (2004) found no difference in the competence ratings between employed fathers and mothers, and Fuegen et al. (2004) found no reliable effects of gender and parental status on evaluators' impressions of the applicant's commitment in one of their two samples of university students. More generally, many of their results were inconsistent across their dependent variable measures. While these studies suggest that a motherhood penalty may exist, the inconsistent pattern of results fails to conclusively demonstrate systematic discrimination on the basis of motherhood. Status characteristics theory offers reasons for these inconsistencies and, more important, allows us to generate precise predictions about when and to what extent motherhood will

that the mother leaves early to attend to children, while the father leaves early to meet clients. In our laboratory experiment we are able to measure the ability standards evaluators use to rate applicants, allowing for an evaluation of the status-based discrimination argument. For a more detailed discussion of the differences between statusbased and statistical discrimination, see Correll and Benard (2006). A variation of statistical discrimination theory dispenses with the assumption that groups of workers vary in their average marginal productivity (Aigner and Cain 1977). Instead, this formulation assumes that the variance of employers' estimates of worker productivity is greater for women and minorities, and that employers are risk averse. As a result, rational employers are again presumed disproportionately to hire white men. The noisier signal of productivity for women and members of minority groups is assumed to obtain because (1) miscommunication is more likely to occur between members of different groups than members of the same group, so that (usually white and male) employers receive clearer information from white male applicants than from other applicants, and (2) white males are more likely to use personal contacts to acquire jobs, and these contacts are assumed to pass accurate information about the applicant to the employer (Oettinger 1996). As our laboratory experiment holds the quality and source of information about applicants constant across conditions, we are also able to eliminate this version of statistical discrimination as a possible explanation. 


\section{American Journal of Sociology}

lead to evaluative biases. By testing these predictions, this study contributes an explanation for the inconsistent evidence yielded in past studies and offers a more complete account of whether and how motherhood serves as a source of disadvantage.

One strength of status characteristics theory is that it delineates a set of propositions that specify the circumstances under which status characteristics have their effects and the relative strength of their impact under differing conditions. For example, according to the "salience" proposition, motherhood will only lead to evaluative biases when it differentiates those in the setting (some are mothers and some are not) or if it is believed to be relevant to the task at hand. Ironically, but consistent with the salience proposition, some work-family policies that are intended to ameliorate the effects of motherhood on workplace outcomes may actually limit the career mobility and wages of women who take advantage of them by making motherhood status highly salient. Glass (2004) found that mothers employed in professional and managerial jobs who participated in programs such as telecommuting experienced lower wage growth compared with otherwise similar mothers who avoided such programs (but see also Weeden 2005). In the Fuegen et al. (2004) study described above, evaluators evaluated only one applicant. Since motherhood was not a differentiating characteristic in this study, it is likely that motherhood was not salient when applicants were evaluated. ${ }^{3}$

In the Cuddy et al. (2004) study evaluators did rate more than one "consultant," and the consultants differed in parental status, thereby making parental status salient. In all conditions, an "experimental consultant" was presented as being 32 years old with an MBA and a long commute. Depending on condition, this consultant was further described as either male or female and as a parent or not. Participants also rated two "filler" consultants who had no children and a BS degree. One was described as a middle-aged woman with a long commute and the other as a young man with a short commute. Between-subject comparisons were made to compare the ratings of the experimental consultants across condition. Including the filler profiles served to make parental status salient, but it also made several other status characteristics salient simultaneously (gender, age, parental status, level of education). According to status characteristics theory, the aggregated expectations individuals form for actors

\footnotetext{
${ }^{3}$ Salience-the requirement that a characteristic, such as parent status, differentiates applicants-is a scope condition of our theory. This narrows the range of settings to which our theory applies, but not in a way that substantially limits the applicability of the theory when considering hiring decisions. This is because the overwhelming majority of hiring processes include comparisons of multiple résumés rather than an examination of applications sequentially (i.e., evaluating applications one at a time without ever directly comparing them).
} 
in a setting are impacted by all of the salient status information, but additional pieces of consistent status information have a declining marginal impact on overall expectations (Berger et al. 1977). Therefore, if we first notice that a person has an MBA, and then notice that she also does not have children (an additional piece of positive status information) the effect of being childless on our overall expectations for her would be less than it would have been if parental status were the only salient status information in the setting. Thus, an experiment that simultaneously varies multiple status characteristics is not the most efficient for detecting whether motherhood status produces the predicted effects.

Consistent with theory presented here, we make parental status salient by having evaluators rate a pair of applicants, one parent and one nonparent. All other status information is kept constant. Before describing the experimental design in further detail, we first turn to the literature on cultural conceptions of motherhood to provide preliminary evidence that motherhood is a status characteristic in U.S. society.

\section{Motherhood as a Status Characteristic}

To understand how motherhood might function as a devalued status characteristic in workplace settings, it is helpful to broaden the conventional usage of "performance expectations." The theory argues that since highstatus actors are expected to offer more competent performances, they are often given behavioral and evaluative advantages compared with lowstatus actors. However, the theory implies that any factor that increases the relative expectation about the capacity of a person to perform in a setting should advantage her/him in that setting (Berger, Cohen, and Zelditch 1966, 1972). Expectations about performance capacity have at least two dimensions: competence (or ability) and effort (Heider 1958). While researchers typically focus on the competence dimension, cultural beliefs about the relative effort that social groups exert in task situations can also be the basis for forming differentiated performance expectations. Indeed, some of the earliest descriptions and examples of status characteristics relied on the idea that anticipated effort impacts performance expectations (Berger et al. 1966, 1972). For example, when explaining why social class is a status characteristic, Berger et al. (1966, pp. 33-34), describe beliefs that the "white collar class" is "more industrious" and "more energetic" than the lower class.

In considering evidence for why motherhood might operate as a status characteristic, it is logically difficult to see why taking on the mother role should affect a person's underlying ability or competence, although there is some evidence that cultural beliefs do associate motherhood with a lessening of ability (see Crittenden 2001). There is, however, considerable 
American Journal of Sociology

evidence that contemporary cultural beliefs include assumptions that employed mothers are less committed to work than nonmothers and, consequently, put less effort into it (for a detailed review see Ridgeway and Correll 2004). While commitment and effort are not synonymous, when evaluating potential employees, employers likely use perceived commitment as a proxy for anticipated future effort.

Motherhood affects perceptions of competence and commitment because contradictory schemas govern conceptions of "family devotion" and "work devotion" (Blair-Loy 2003, p. 5). Contemporary cultural beliefs about the mother role include a normative expectation that mothers will and should engage in "intensive" mothering that prioritizes meeting the needs of dependent children above all other activities (Hays 1996; Kobrynowicz and Biernat 1997; Blair-Loy 2003). The cultural norm that mothers should always be on call for their children coexists in tension with another widely held normative belief in our society that the "ideal worker" be unencumbered by competing demands and be "always there" for his or her employer (Acker 1990; Hays 1996; Williams 2001; BlairLoy 2003). According to this "ideal worker" belief, the best worker is the "committed" worker who demonstrates intensive effort on the job through actions that appear to sacrifice all other concerns for work (Epstein et al. 1999; Williams 2001). Examples include a willingness to drop everything at a moment's notice for a new work demand, to devote enormous hours to "face time" at work, and to work late nights or weekends. While it has often been observed that "face time" and long hours are not necessarily associated with actual worker performance or productivity (e.g., Epstein et al. 1999), in the contemporary organization of work, they function as a cultural sign of the effort component of performance capacity. Normative conceptions of the "ideal worker" and the "good mother" create a cultural tension between the enactment of the motherhood role and the enactment of the committed worker role. The cultural logic of "intensive" mothering in U.S. society today assumes that the "good mother" will direct her time and emotional energy toward her children without limit (Hays 1996; Blair-Loy 2003). By this cultural definition, then, a good mother must give less effort and priority to work demands and therefore be a less committed worker.

It is important to keep in mind that the tension between these two roles occurs at the level of normative cultural assumptions, and not necessarily at the level of mothers' own commitment to work roles. In fact, if work commitment is measured by the importance people attach to their work identities-either absolutely or relative to other identities, such as family identities-no difference is found in commitment between mothers and nonmothers (Bielby and Bielby 1984). It is the perceived cultural tension 
between these two roles that leads us to suggest that motherhood is a devalued status in workplace settings.

\section{EMPIRICAL PREDICTIONS}

\section{Motherhood Penalty}

Our main empirical predictions are that job applicants who are presented as mothers will be rated as less competent, less committed to paid work, less suitable for hire and promotion, and deserving of lower starting salaries compared with otherwise equal women who are not mothers. We expect that the competence and commitment ratings will mediate the evaluation variables. In other words, we predict evaluators will offer mothers lower salaries and other rewards because they assume that they are less competent and committed than other kinds of workers. We also expect that mothers will be judged by a harsher standard.

\section{Additional Factors Affecting Worker Evaluations}

The effect of fatherhood.-Unlike the motherhood role, being a good father is not seen as culturally incompatible with being an ideal worker. In fact, as Townsend (2002) describes, being a good father and a good employee are part of the "package deal" defining what it means to be a man. Therefore, since the "good father" and "ideal worker" are not perceived to be in tension, being a parent is not predicted to lead to lower workplace evaluations for fathers.

In fact, research on the "marriage premium" for men's wages, one of the most robust empirical findings in labor economics, suggests that fathers might experience advantages in labor market outcomes (Hersch and Stratton 2000; Loh 1996; Korenman and Neumark 1991; Hill 1979). Labor economists frequently report that married men earn higher wages than unmarried men, and speculate that this may occur for one of the following reasons: (1) more productive men marry at greater rates (attributing the marriage premium to selection bias), (2) men become more productive following marriage (due to labor market specialization by men and domestic specialization by women), or (3) employers favor married men (due to gender bias). Empirical investigations cast doubt on the selection bias (Loh 1996; Korenman and Neumark 1991) and productivity (Hersch and Stratton 2000; Loh 1996) explanations.

Our theory suggests that the marriage premium may actually be, in part, a fatherhood premium. Cultural conceptions of fatherhood in the United States often include the right to a "family wage" bonus to ensure that married men serve as breadwinners for their families (Orloff 1996; 
American Journal of Sociology

Hill 1979). There is already some evidence for this: when children under six are included into men's wage equations, they exert a positive and significant effect on wages and reduce the magnitude of the marriage premium (e.g., Hersch and Stratton 2000). While our theory focuses on the hypothesized wage penalty for mothers, it is consistent with a wage premium for fathers.

The effects of race and gender.-Since race and gender are also status characteristics, we would expect that if race and/or gender were salient when applicants were evaluated, applicants who are female and/or African-American would be rated as less hirable and promotable and offered lower salaries than white male applicants. However, since participants will evaluate a pair of applicants who are the same gender and race, race and gender should not be salient. It is of course possible that participants will implicitly compare the applicants to others whom they imagine are being evaluated and, in so doing, that they will draw on status beliefs about gender and race, leading to biased ratings. To the extent that this occurs, it is possible that a main effect of race and gender on evaluations will be found, although these effects should be weaker and less reliable than the effects of motherhood status.

We manipulate gender so that we can evaluate the claim above that men are not penalized in the workplace for being fathers. We manipulate race in the laboratory experiment so that we can evaluate whether our argument holds for both white and African-American applicants. ${ }^{4}$ Our theory predicts that mothers, both African-American and white, will experience evaluative biases in workplace settings. However, Anderson et al. (2003) report that past studies using survey data are inconclusive about how the magnitude of the motherhood penalty differs for African-American and white women. Given this inconsistency and the differences in workplace histories and experiences of African-American and white women, it is important to evaluate whether status-based discrimination works similarly for both groups, rather than assume that race does not impact this process. Our laboratory experiment design will allow us to assess whether the motherhood penalty accrues to both African-American and white women and to compare the magnitude of any penalty found. The design will also allow us to compare the ratings of childless women to childless men and the ratings of mothers and fathers. While not the central focus, these comparisons are important since responses to labor market data on the gender wage gap compare wages for men and women, often controlling for parental status (e.g., Crittenden 2001; Venable 2002).

${ }^{4}$ We do not vary race in the audit study, as we describe below. 
Motherhood Penalty

\section{THE LABORATORY EXPERIMENT}

Paid undergraduate volunteers rated a pair of equally qualified, samegender (either male or female), same-race (either African-American or white) fictitious job applicants, presented as real, who differed on parental status. Pairing application materials by race and gender generates four experimental conditions where participants rate one parent and one nonparent applicant who are either African-American men, African-American women, white men, or white women. Male and female participants were randomly assigned to one of these four conditions, and parental status was counterbalanced across the two members of the applicant pair (i.e., one member of the pair was presented as a parent to half of the participants in each condition, and the other member was the parent for the other half of the participants in that same condition). Thus, the design consisted of three between-subjects factors (gender of participant, gender of applicant pair, and race of applicant pair) and one within-subjects factor (parental status). ${ }^{5}$ We make no predictions about the effect of participant gender on applicant ratings, although the design allows us to assess if male and female evaluators react differently to parental status.

The study included 192 participants ( 84 men and 108 women), between 19 and 28 per condition. Four participants $(2.1 \%)$ were suspicious about some aspect of the study, and consequently their data were excluded prior to analysis, creating an effective sample size of 188 . Rejection rules were conservative and established beforehand. All analyses were also conducted with all available data, and no substantive differences were found.

\section{The Use of Undergraduates}

The laboratory experiment features a highly controlled setting with a diverse set of measures, allowing us to generate data that are well suited for evaluating our theoretical mechanism. In particular, the laboratory

\footnotetext{
5 "Between-subjects" factors are those that do not vary within an experimental condition, such as participant gender, whereas "within-subjects" factors do vary. For example, in this experiment parental status is a within-subject factor since it varies across the two members of the applicant pair. Since the primary purpose of this project is to assess the effect of parental status on the ratings and evaluations of applicants, it is important that parental status be measured as a within-subjects comparison, which is more efficient than between-pair comparisons (Cohen 1988). This efficiency rationale might suggest an alternate design, where applicant race and gender were also measured within subject. In this alternate design male and female participants would evaluate eight sets of application materials-a parent and nonparent applicant from each race/ sex combination. Pretesting established that this alternate design aroused suspicion since participants were required to examine eight sets of very similar materials. Even though between-subject comparisons are less efficient estimators they are nonetheless unbiased.
} 
American Journal of Sociology

setting ensures that we can maintain sufficient control over factors that would interfere with tests of our hypotheses (e.g., no other people in the room to prime other status characteristics, no telephone or other distractions present). However, it is not feasible to convince approximately 200 actual employers to visit the laboratory and spend one hour participating in an experiment. Therefore, by necessity we must rely on a sample of undergraduates in order to obtain a complete test of our theoretical claims regarding the discrimination mechanism. Understanding this mechanism is important if the goal is to find ways to reduce the disadvantages mothers face.

The theory presented here implies that to the extent that employers share the belief that mothers are less committed to or competent in workplace settings, they too will subtly discriminate against mothers. Qualitative research suggests that employers do, in fact, share this belief and discriminate against mothers in a range of settings (Blair-Loy 2003; Crittenden 2001; Kennelly 1999). For example, Blair-Loy quotes a chief financial officer who acknowledges deliberately rejecting women applicants on the basis of parent status. Her source conceded, "I find myself choosing men here every day over a woman with a child. If I had kids, I might not have made the same commitment to my job" (Blair-Loy 2003, pp. 119-20). Quantitative research also suggests that managers and student evaluators offer similar appraisals of applicants and that evaluators respond similarly to real and hypothetical applicants (Cleveland and Berman 1987; Cleveland 1991; Olian and Schwab 1988).

To assess more directly the extent to which employers discriminate against mothers, we conducted an audit study of actual employers. We describe this study and its results after presenting the results from the laboratory experiment. While the audit study cannot assess the mechanism of discrimination, it was designed to allow for comparability with the laboratory experiment, and provides evidence of the real-world implications of the argument evaluated here.

\section{Procedure}

Participants came to the lab individually, read a description of a company that was purportedly hiring for a midlevel marketing position, and examined application materials for two applicants for the position who differed on parental status but were otherwise similar. They examined the applicant files one at a time, and we counterbalanced which file, the parent or nonparent, they viewed first. After reviewing an applicant's file, participants immediately completed an "initial impressions" survey for that applicant, which contained items that allow us to assess whether the participants in this study view motherhood as a status characteristic 
(see "dependent measures" below). On the same instrument, participants were asked to provide a list of pros and cons for each applicant, a task intended to entice them to look more closely at the applicants' materials before proceeding to the next stage of evaluation. Participants were next instructed to look at the application materials more closely and complete an "applicant evaluation sheet" for each candidate. This instrument contained our ability standard and evaluation measures, described below. Before leaving the lab, participants answered a series of free response items to assess whether the experimental manipulations were successful and to determine if they were suspicious of some aspect of the study. They were also briefly interviewed as a further check on experimental manipulations and suspicion, and then they were debriefed and paid.

\section{Cover Story}

Participants were told that a California-based start-up communications company was conducting an employment search for a person to head up its new East Coast marketing department. They heard that the communications company was interested in receiving feedback from younger adults since young people are heavy consumers of communications technology. To further increase their task orientation, participants were told that their input would be incorporated with the other information the company collects on applicants and would impact actual hiring decisions. ${ }^{6}$ Participants then read about the requirements of the marketing position and the proposed salary range $(\$ 135,000-\$ 180,000)$.

\section{Application Materials}

Participants inspected an applicant file for each of the two applicants. Other than varying first names to manipulate race and gender (see below),

\footnotetext{
${ }^{6}$ The decision to use deception in experimental settings requires a careful weighing of the potential costs and benefits. As others have noted, "Experimenters often find themselves in the troublesome position of concealing the truth from their subjects in order to reveal a truth about human behavior" (Aronson et al. 1990, p. 89). If we did not use deception in this study, participants may have provided socially desirable answers (to avoid appearing to discriminate against mothers) or may not have taken the task seriously (and thus answered carelessly, rather than in a way that revealed their true preferences). Both of these would have suppressed our ability to detect real discrimination against mothers. We believe that the costs of a relatively brief (the deception and the reasoning behind it was fully explained to participants at the end of the study, meaning that participants were deceived for less than an hour in most cases) and mild (the deception did not distress the participants or violate their privacy) use of deception were outweighed by the increased risk of concluding that mothers do not face discrimination when they actually do.
} 
American Journal of Sociology

the files were identical across condition. The files contained three items: a short memo, a "fact sheet," and a résumé. The memos were similar to those used by Cuddy et al. (2004) and contained a few brief notes purportedly from a human resources staff member at the hiring company who conducted a short screening interview with the applicant. The memos and the résumés were used to manipulate parental status as described below. The "fact sheet" summarized relevant information about the potential employees (such as college grade point average) that was not presented on the résumé. The résumés listed the applicant's career goals, educational history, past work experience, and other relevant activities. The résumés indicated that the applicants had bachelor's degrees from one of two large midwestern universities and had approximately seven years of work experience. Both applicants were presented as highly productive by including "results" on the résumé, such as "increased division sales by $10 \%$ between 2000 and 2002." The fact sheet and the résumés were used to establish that the candidates were equally productive in their past jobs and that they had equivalent skills and backgrounds. One challenge of this study was to create two sets of materials that were of equivalent quality without being suspiciously similar.

Prior to the actual experiment, we pretested the two versions of the materials to assess whether they were of equivalent quality. At this stage, race, gender, and parental status information was not available to evaluators so that we could determine whether the résumés were perceived to be equal in the absence of the status manipulations to be employed in the actual experiment. A different sample $(N=60)$ drawn from the same population as in the actual experiment rated these two "template" résumés, one at a time, using seven-point scales ranging from "not at all" to "extremely" capable, efficient, skilled, intelligent, independent, self-confident, warm, and sincere. No significant differences were found between participants' ratings of the two résumés on any of these eight traits. Participants also indicated which of the two applicants appeared more qualified for a marketing position with a new start-up company, and no significant association was found between résumé template and being more qualified $\left(\chi^{2}=1.79, d f=3\right)$, indicating that one applicant did not appear significantly more qualified than the other. Nonetheless, to ensure that differences in résumés were not systematically impacting the results, parental status was counterbalanced in the actual experiment across the two versions of the résumés for each condition.

Race and Gender Manipulations

Following Bertrand and Mullainathan (2003), the race and gender of applicants were manipulated by altering first names on the applicant files. 
Bertrand and Mullainathan (2003) used birth certificate data to generate a list of names commonly given to white and African-American children in the mid-1970s and then pretested these names to establish that they evoked the race and gender attributions predicted (see Bertrand and Mullainathan 2003, app. A). We used the following first names taken from this list: Allison and Sarah (white females), Ebony and Latoya (AfricanAmerican females), Tyrone and Jamal (African-American males), and Brad and Matthew (white males). Each member of the applicant pair, regardless of race or gender, had one of two last names that were consistent across condition.

\section{Parental Status Manipulation}

Parental status was manipulated on the résumé and on the human resources memo. The résumé for the parent member of the applicant pair listed "Parent-Teacher Association coordinator" under the heading "other relevant activities." The nonparent was instead described as the fundraiser for his/her neighborhood association. Fuegen et al. (2004) successfully used a similar manipulation to indicate parental status. Following Cuddy et al. (2004), the memo for the parent member of the pair included the following phrase: "Mother/father to Tom and Emily. Married to John/ Karen." The nonparent was described as simply "married to John/Karen."

\section{Dependent Measures}

According to the theory, if motherhood operates as a status characteristic, then mothers will be perceived as less competent or committed than nonmothers. As a result, mothers will be judged by a harsher standard than other potential employees and will be viewed as less hirable, less promotable, and deserving of lower starting salaries. To evaluate this argument, there are eight dependent measures: two that measure the traits of competence and commitment, two that measure the ability standard participants used to judge the applicants, and four that serve as our key evaluation measures. The eight measures are moderately correlated, with correlations ranging .25-.45.

Competence and commitment measures.-During the first phase of eval-

\footnotetext{
${ }^{7}$ We did not give the spouses and children of the African-American applicants "black" names. The goal was to make race of applicant salient, but hold all other factors constant. While one of the applicants was presented as a parent, the application materials for the other member of the pair made no mention of children, although she or he was described as married. We use the phrases "nonparent" or "childless" for convenience even though it would be more correct, even if awkward, to refer to these applicants as "women (or men) who did not give evidence of being a parent."
} 


\section{American Journal of Sociology}

uation, participants rated applicants on a series of items, including items intended to measure the extent to which they viewed the candidates as competent. Following Cuddy et al. (2004) we created a composite competence measure by calculating a weighted average of participants' ratings of the applicants on seven-point scales ranging from "not at all" to "extremely" capable, efficient, skilled, intelligent, independent, self-confident, aggressive, and organized (mean $=5.48, \mathrm{SD}=.69$, alpha $=.85){ }^{8}$

To measure perceived commitment, we included a single-item question on the "applicant evaluation sheet" which asked participants how committed they thought the applicant would be relative to other employees in similar positions at the company. They were given 10 choices ranging from "more committed than $0 \%$ of other employees" to "more committed than $99 \%$ of other employees." On average participants viewed the applicants as more committed than $74.7 \%$ of other similar employees $(\mathrm{SD}=18.0 \%)$. The main empirical prediction is that if motherhood is a status characteristic, the mean competence and commitment ratings should be lower for mothers than for nonmothers.

Ability standard measures.-Participants answered two items on the second phase of evaluation designed to provide ability standard measures. The first question was "in what percentile would the applicant need to score on his/her management profile exam in order for you to consider him/her for employment?" Participants were given choices ranging from the fifth to the ninety-ninth percentile. The "management profile exam" was described to participants as providing evidence about potential for advancement. The mean for the score-required item was $68.7(\mathrm{SD}=30.3)$, indicating that applicants would need, on average, to score in approximately the sixty-ninth percentile or higher in order to be hired.

Participants were further asked, "How many days could this applicant arrive late or leave early per month before you would no longer recommend him/her for hire?" The mean for the days late item was 3.43 days $(\mathrm{SD}=2.12)$. According to the status-based discrimination mechanism, if motherhood operates as a status characteristic, mothers will be judged by a harsher standard than nonmothers. They will be required to score in a higher percentile than nonmothers before being considered hirable and will be allowed fewer days of being late or leaving early.

Evaluation measures.-Four evaluation measures were included on the applicant evaluation sheet. Participants were asked what salary in dollars they would recommend for each applicant if the applicant were hired.

\footnotetext{
${ }^{8}$ While we followed Cuddy et al. in creating our competence composite variable, the results presented in this article do not hinge on the exact composition of the variable. That is, individual items produce qualitatively similar results, as do composites created from smaller subsets of the items.
} 
Motherhood Penalty

Recall that the participants were told that the proposed salary range was $\$ 135,000-\$ 180,000$. The mean salary recommended was $\$ 145,000$ $(\mathrm{SD}=\$ 22,400)$. Participants were also asked to estimate the likelihood that an applicant would be subsequently promoted if hired. Responses were on a four-point scale ranging from "most certainly will NOT be promoted" to "most certainly will be promoted," with a mean response of $3.14(\mathrm{SD}=.67)$, suggesting that applicants, if hired, were generally viewed as moderately promotable. Participants were further asked if they thought the applicant, if hired, should be recommended for a managementtraining course designed for those with strong advancement potential. Overall, $83.5 \%$ of applicants were recommended for this course. Finally, participants were asked for each applicant if they would recommend her/ him for hire. Overall, $66.5 \%$ of applicants were recommended for hire. Since they were evaluating two applicants (one at a time), it was possible at this stage for participants to recommend hiring both applicants, although most did not-112 participants recommended only one of two applicants for hire, whereas 7 recommended none and 69 recommended both. The main empirical predictions are that mothers will be offered lower starting salaries, be rated as less promotable, be less likely to be recommended for management, and be less likely to be recommended for hire.

\section{LABORATORY EXPERIMENT RESULTS}

We first address the central question of whether mothers face unique disadvantages in workplace evaluations. We then conduct ancillary analyses to see if participant gender or applicant race qualify the results. Finally, we conclude with an analysis designed to assess whether the competence and commitment ratings of applicants mediate the effect of motherhood on workplace evaluations.

\section{Is There a Motherhood Penalty?}

Table 1 provides means or proportions of the participants' ratings of the applicants, along with corresponding paired $t$-tests to compare means and $Z$-tests to compare proportions. At this stage we pooled the data for male and female subjects and for African-American and white applicants to highlight the main comparison motivating this study-the comparison of mothers to nonmothers. In the multivariate models below, we decompose the results by subject gender and race of applicant.

Ratings of mothers and nonmothers.-The first two columns of table 1 compare the ratings of female applicants who are mothers with those 
American Journal of Sociology

TABLE 1

Means or Proportions of Status, Standards, and Evaluation Variables by Gender and Parental Status of Applicant

\begin{tabular}{|c|c|c|c|c|}
\hline & \multicolumn{2}{|c|}{ Female Applicants } & \multicolumn{2}{|c|}{ Male Applicants } \\
\hline & Mothers & Nonmothers & Fathers & Nonfathers \\
\hline Competence...$\ldots \ldots \ldots \ldots$ & $\begin{array}{l}5.19 * * \\
(.73)\end{array}$ & $\begin{array}{l}5.75 \\
(.58)\end{array}$ & $\begin{array}{c}5.51 \\
(.68)\end{array}$ & $\begin{array}{l}5.44 \\
(.66)\end{array}$ \\
\hline Commitment & $\begin{array}{l}67.0 * * \\
(19.1)\end{array}$ & $\begin{array}{l}79.2 \\
(15.2)\end{array}$ & $\begin{array}{l}78.5 * * \\
(16.3)\end{array}$ & $\begin{array}{l}74.2 \\
(18.6)\end{array}$ \\
\hline Days allowed late $\ldots . \ldots \ldots$ & $\begin{array}{l}3.16^{* *} \\
(1.98)\end{array}$ & $\begin{array}{c}3.73 \\
(2.01)\end{array}$ & $\begin{array}{l}3.69 * * \\
(2.55)\end{array}$ & $\begin{array}{c}3.16 \\
(1.85)\end{array}$ \\
\hline$\%$ score required on & & & & \\
\hline $\operatorname{exam} \ldots \ldots \ldots \ldots \ldots$ & $\begin{array}{l}72.4^{* * *} \\
(27.5)\end{array}$ & $\begin{array}{c}67.9 \\
(27.7)\end{array}$ & $\begin{array}{l}67.3 \\
(32.7)\end{array}$ & $\begin{array}{c}67.1 \\
(33.0)\end{array}$ \\
\hline Salary recommended $(\$) \ldots$ & $\begin{array}{c}137,000 * * \\
(21,000)\end{array}$ & $\begin{array}{l}148,000 \\
(25,000)\end{array}$ & $\begin{array}{c}150,000 * * \\
(23,000)\end{array}$ & $\begin{array}{l}144,000 \\
(20,700)\end{array}$ \\
\hline $\begin{array}{l}\text { Proportion recommend for } \\
\text { management } \ldots \ldots \ldots \ldots \ldots\end{array}$ & $.691^{++}$ & .862 & $.936^{+}$ & .851 \\
\hline $\begin{array}{l}\text { Likelihood of promo- } \\
\quad \text { tion } \ldots \ldots \ldots \ldots \ldots \ldots \ldots\end{array}$ & $\begin{array}{l}2.74 * * \\
(.65)\end{array}$ & $\begin{array}{l}3.42 \\
(.54)\end{array}$ & $\begin{array}{l}3.30 * \\
(.62)\end{array}$ & $\begin{array}{l}3.11 \\
(.70)\end{array}$ \\
\hline $\begin{array}{l}\text { Proportion recommend for } \\
\text { hire } \ldots \ldots \ldots \ldots \ldots \ldots \ldots\end{array}$ & $.468^{++}$ & .840 & $.734^{+}$ & .617 \\
\hline $\begin{array}{l}\text { NotE. }- \text { SDs in parentheses. } 9 \\
\text { For this table, the data for male } \\
\text { All values reported to three signif } \\
{ }^{+} Z<.10 \text {, test for difference in } \\
{ }^{++} Z<<.05 \text {. } \\
{ }^{*} P<.10 \text {, test for difference in } \\
{ }^{* *} P<.05 \text {. }\end{array}$ & $\begin{array}{l}\text { rticipants } r \\
\text { female sub } \\
\text { t digits. See } \\
\text { ortions bet } \\
\text { ans between }\end{array}$ & $\begin{array}{l}\text { emale applica } \\
\text { are pooled, as } \\
\text { for variable } d \\
\text { parents and n }\end{array}$ & $\begin{array}{l}\text { and } 94 \text { rate } \\
\text { the data by } \\
\text { ptions. } \\
\text { rents. }\end{array}$ & $\begin{array}{l}\text { e applicants. } \\
\text { of applicant. }\end{array}$ \\
\hline
\end{tabular}

who are nonmothers. As predicted, mothers were judged as significantly less competent and committed than women without children. The competence ratings are approximately $10 \%$ lower for mothers than for nonmothers, and the commitment ratings are about $15 \%$ lower. Mothers were also held to harsher performance and punctuality standards. Mothers were allowed significantly fewer times of being late to work, and they needed a significantly higher score on the management exam than nonmothers before being considered hirable.

Similarly, the evaluation measures show significant and substantial penalties for motherhood. The recommended starting salary for mothers was $\$ 11,000$ (7.4\%) less than that offered to nonmothers, a significant difference. Mothers were also rated as significantly less promotable and were less likely to be recommended for management. Finally, while participants recommend $84 \%$ of female nonmothers for hire, they recommend a significantly lower $47 \%$ of mothers. Recall that when the résumés for the 
two applicants were pretested without any parental status manipulations, no significant differences were found in how they were rated, suggesting that the motherhood manipulation produced the lower ratings found here.

Ratings of fathers and nonfathers.-The last two columns of table 1 compare the ratings of male applicants who are fathers with those who are nonfathers. Our theory predicted that fathers would not experience a fatherhood penalty, and our results are consistent with this prediction. In fact, fathers were actually advantaged on some of these measures. For example, applicants who were fathers were rated significantly more committed to their job than nonfathers. Fathers were allowed to be late to work significantly more times than nonfathers. Finally, they were offered significantly higher salaries than nonfathers.

\section{Multivariate Analysis}

We now turn to multivariate models to evaluate the motherhood penalty hypothesis by estimating the effects of gender of applicant, parental status, and the interaction of gender of applicant with parental status on each of the eight dependent variables. We refer to the interaction term (gender of applicant $\times$ parental status) as the "motherhood penalty interaction." Applicant race and participant gender are included in all models, and standard errors are clustered by participant ID to take into account the nonindependence of observations that results from asking participants to rate applicants in pairs. ${ }^{9}$ Linear regression models are used for the continuous dependent variables. Logistic regression models are estimated for the binary evaluation variables (recommend for management and recommend for hire). Ordered logistic regression, with the proportional odds specification, is used for the ordered categorical evaluation variable, likelihood of promotion. Parental status, gender of applicant, gender of participant, and race of applicant are dummy variables, with parents, females, and African-Americans coded as 1.

The estimated regression coefficients are presented in tables 2, 3, and 4. For all eight dependent variables, the motherhood penalty interaction is significant and is in the predicted direction. Based on this result, we conclude that there is strong support for the main prediction that parental status negatively impacts ratings for female, but not male, applicants. We now describe more precisely the effect of motherhood status on each of the dependent variables.

Commitment and competence.-Table 2 contains estimated regression

${ }^{9}$ Using Mplus 3.1, robust standard errors are computed using the sandwich estimator, which takes into account nonindependence of observations (Muthén and Muthén 19982004). 
American Journal of Sociology

TABLE 2

Estimated Regression Coefficients for the Effects of Gender, Parental Status, and Race on Applicant's Perceived Competence AND COMMitMent

\begin{tabular}{lcc}
\hline \hline \multicolumn{1}{c}{ Independent Variables } & Competence & Commitment \\
\hline Parent $\ldots \ldots \ldots \ldots \ldots \ldots \ldots \ldots \ldots$ & .089 & $5.15 * * *$ \\
& $(.088)$ & $(1.73)$ \\
Female applicant $\ldots \ldots \ldots \ldots \ldots \ldots$ & $.376 * * *$ & $5.68 * *$ \\
& $(.104)$ & $(2.51)$ \\
African-American $\ldots \ldots \ldots \ldots \ldots$ & -.038 & -2.01 \\
& $(.090)$ & $(2.27)$ \\
Female participant $\ldots \ldots \ldots \ldots \ldots$ & .060 & -2.61 \\
& $(.094)$ & $(2.26)$ \\
Motherhood interaction ${ }^{\mathrm{a}} \ldots \ldots \ldots$ & $-.7550 * * *$ & $-17.3 * * *$ \\
& $(.132)$ & $(2.32)$ \\
Intercept ...................... & $5.42 * * *$ & $75.8 * * *$ \\
& $(.100)$ & $(2.55)$ \\
\hline
\end{tabular}

Note. - Robust SEs in parentheses; clustered by participant ID. $N=188$ participants. All values reported to three significant digits. See text for variable descriptions. ${ }^{a}$ Parent $\times$ female applicant.

$* P<.10$.

** $P<.05$.

*** $P<.001$

coefficients and robust standard errors for the effects of the independent variables on competence and commitment. In order to determine the magnitude of the effect of motherhood status on the dependent variables it is necessary to consider the additive effects of parental status, gender of applicant, and the motherhood penalty interaction.

Confirming our prediction, mothers are viewed as less competent than nonmothers. As shown in the left-hand column of table 2, the motherhood penalty interaction is significant and negative, indicating that being a parent lowers the competence ratings for women, but not men. The female applicant dummy variable is significant and positive, implying that women without children are rated as more competent than men without children. While this finding was not predicted, one can imagine several reasons why women without children might be ranked higher than men without children in this setting. Cultural constructions of gender often include beliefs that women want (or even "need") children to feel fulfilled. As a result, participants may assume that women who have apparently forgone childbearing to enter the labor market are extraordinarily committed to work. In contrast, because men are not expected to "need" children, this information does not carry the same impact for men.

A second possibility is that participants may rate nonmothers more highly as a way to compensate for their discrimination against mothers. 
Research has shown that people tend to follow an implicit strategy of maintaining "moral credentials" in which indulgence in discrimination toward one target is coupled with antidiscriminatory action toward another target (Monin and Miller 2001). Thus, because participants rated a woman without children and a woman with children simultaneously, they may have attempted to justify discriminating against the mother by unconsciously embellishing their ratings of the nonmother. The higher rating for women without children may thus occur because participants are forced to choose between a mother and a nonmother. We are not able to adjudicate between these or other possible accounts with the available data. ${ }^{10}$ However, these accounts are empirically testable and merit consideration in future research. We also note that this result does not contradict our primary claim that mothers face evaluative biases in the workplace.

Participants also perceived mothers as less committed than other applicants: the motherhood penalty interaction is significant and negative in the model predicting commitment ratings (right-hand column of table 2). In this model, the female applicant coefficient is again significant and positive, providing further evidence that women without children experience what might be called a "childless bonus." There is also a positive and significant main effect for parental status, implying that fathers are actually rated as more committed than nonfathers by about 5 percentage points. Mothers, by contrast, suffer a reduction of about 6.4 percentage points in their commitment ratings compared with childless men (sum of the main effects of parental status and applicant gender and the interactive term) or about 12.1 percentage points compared with childless women (sum of the main effect of parental status and the interactive term).

Status characteristics trigger beliefs about performance capacity, and these beliefs derive from expectations about anticipated effort and ability (competence). Our results show that mothers are not only viewed as less committed to paid work, they are also seen as having less workplace ability. The decreased competence and commitment ratings for mothers suggest that motherhood operates as a status characteristic.

\footnotetext{
${ }^{10}$ An anonymous reviewer suggested an additional component of status-based discrimination against mothers. It may be the case that employers perceive current fertility as a signal of future fertility, and thus apparent commitment to the labor market. The large gap between women with children and women without children may occur in part because employers expect women with children to have more children and decrease attachment to the labor market as a result. Furthermore, as this reviewer pointed out, if current fertility functions as a signal of future fertility, we would not expect ratings of competence and commitment to fully mediate the results. This is because evaluators may expect productivity to decline more in the future for mothers (upon having more children) than for nonmothers. Equal ratings of current productivity thus do not guarantee equal estimates of future productivity.
} 
American Journal of Sociology

Ability standards.-According to the status-based discrimination argument, mothers will be held to stricter standards than other kinds of applicants. Table 3 contains the estimates for the effects of the independent variables on the ability standard items. Consistent with predictions, mothers were held to a stricter performance standard. The motherhood interaction is significant and positive in the model predicting the required test score, while the main effects of gender of applicant and parental status are insignificant (right-hand column of table 3). This shows that participants would require mothers (but not fathers) to score higher on a test of management ability than other applicants before considering them for a job.

Participants were also asked how many days an applicant could be late or leave early before they would no longer consider hiring them. We expected that participants would allow mothers less flexibility than other types of employees. As can be seen in the left-hand column of table 3 , this prediction is supported by the significant and negative motherhood penalty interaction. There is also a significant, positive main effect for being a parent and for being female. Thus, childless women and fathers are allowed to be late more frequently without its impacting their perceived suitability for hire. However, mothers are evidently held to a higher standard of punctuality, being allowed fewer days of being late.

Workplace evaluations.-In table 4, the motherhood penalty interaction is significant and negative across all four models, indicating that mothers, relative to other applicants, are believed to deserve lower salaries and to be less suitable for hiring, promoting, and training for management. In the model predicting likelihood of promotion, the main effect of parental status is marginally significant and positive, while the motherhood penalty interaction is significant and negative, indicating that the negative effect of parental status on perceptions of promotability accrues only to women.

Mothers are also less likely than other types of applicants to be recommended for management (second column of table 4). If we convert the regression coefficient for the parental status variable to an odds ratio, fathers are 1.83 times more likely to be recommended for management than childless men, a difference that is marginally significant. For female applicants, childless women are 8.2 times more likely than mothers to be recommended for management. ${ }^{11}$

Being a mother also lowers the odds of an applicant's being recommended for hire. The main effect of parental status is not significant, indicating that on this measure fathers are not advantaged over men

${ }^{11}$ The inverse log of $.605-2.716=.122$. To state as the odds for childless women compared to mothers, we inverted this ratio $(1 / .122=8.2)$. A similar calculation is made for the odds of being hired. 
Motherhood Penalty

TABLE 3

Estimated Regression Coefficients for the Effects of Gender, Parental Status, and Race on Ability Standard Variables

\begin{tabular}{ccc}
\hline \hline Independent Variables & Days Allowed Late & Test Score Required (\%) \\
\hline Parent $\ldots \ldots \ldots \ldots \ldots \ldots \ldots$. & $.515 * * *$ & 1.03 \\
& $(.137)$ & $(.968)$ \\
Female applicant $\ldots \ldots \ldots \ldots$ & $.572 * *$ & 1.25 \\
& $(.294)$ & $(4.52)$ \\
African-American $\ldots \ldots \ldots \ldots$ & -.361 & -4.06 \\
& $(.294)$ & $(4.38)$ \\
Female participant $\ldots \ldots \ldots$. & .234 & $-9.44 * *$ \\
& $(.289)$ & $(4.30)$ \\
Motherhood interaction ${ }^{\mathrm{a}} \ldots$ & $-1.10 * * *$ & $3.56 * * *$ \\
& $(.213)$ & $(1.21)$ \\
Intercept .................. & $3.22 * * *$ & $73.7 * * *$ \\
& $(.322)$ & $(4.27)$ \\
\hline
\end{tabular}

Note. - Robust SEs in parentheses; clustered by participant ID. $N=188$ participants. All values reported to three significant digits. See text for variable descriptions.

${ }^{\text {a }}$ Parent $\times$ female applicant.

$* P<.10$.

** $P<.05$.

*** $P<.001$

without children. The main effect for being a female applicant is again highly significant. Stated as an odds ratio, childless women are 3.35 times more likely to be recommended for hire than childless men. However, childless women are especially advantaged compared to mothers, being over six times more likely to be recommended for hire.

Mothers are also offered lower starting salaries than other types of applicants, as indicated by the significant, negative coefficient for the motherhood interaction term. Using the values in table 4 to calculate predicted values, we find that childless men were recommended an average salary of approximately $\$ 148,000 .{ }^{12}$ Fathers were offered a significantly higher salary of approximately $\$ 152,000$. In the past, employers legally paid fathers a "family wage" that was higher to accommodate their supposed breadwinner role. Cultural beliefs emphasizing the importance of male-headed households provided the normative underpinnings of this "fatherhood bonus" (Orloff 1996). The results suggest that, while the family wage is formally extinct in the United States, it may informally survive in the form of salary premiums ostensibly motivated by productivity. For

\footnotetext{
${ }^{12}$ These predicted values are for male subjects (gender of subject $=0$ ) and white applicants (African-American $=0$ ). The same pattern of predicted values is found when calculations are made with female subject and/or African-American applicant data. That is, regardless of gender of subject or race of applicant, mothers are offered significantly lower starting salaries.
} 
TABLE 4

Estimated Regression Coefficients for the Effects of Gender, Parental Status, and Race on Evaluation Variables

\begin{tabular}{|c|c|c|c|c|}
\hline Independent Variables & $\begin{array}{c}\text { Promotion Likelihood } \\
\text { (Ordered Logistic Estimates) }\end{array}$ & $\begin{array}{l}\text { Management Training? } \\
\text { (Binary Logistic Estimates) }\end{array}$ & $\begin{array}{c}\text { Hire? } \\
\text { (Binary Logistic Estimates) }\end{array}$ & $\begin{array}{c}\text { Recommended Salary } \\
\text { in Thousands } \\
\text { of Dollars } \\
\text { (Linear Estimates) }\end{array}$ \\
\hline Parent $\ldots \ldots \ldots \ldots \ldots \ldots \ldots$ & $\begin{array}{l}1.03 * \\
(.545)\end{array}$ & $\begin{array}{l}.605 * \\
(.321)\end{array}$ & $\begin{array}{c}.570 \\
(.366)\end{array}$ & $\begin{array}{l}4.47 * * * \\
(1.84)\end{array}$ \\
\hline Female applicant $\ldots \ldots \ldots \ldots$ & $\begin{array}{l}.256 \\
(.425)\end{array}$ & $\begin{array}{l}1.009 * * * \\
(.319)\end{array}$ & $\begin{array}{l}1.21 * * * \\
(.365)\end{array}$ & $\begin{array}{c}2.56 \\
(3.18)\end{array}$ \\
\hline African-American $\quad . . \ldots \ldots . .$. & $\begin{array}{l}.309 \\
(.299)\end{array}$ & $\begin{array}{l}-.211 \\
(.218)\end{array}$ & $\begin{array}{l}-.163 \\
(.197)\end{array}$ & $\begin{array}{l}-6.80 * * \\
(2.94)\end{array}$ \\
\hline Female participant $\ldots \ldots \ldots$ & $\begin{array}{l}.496 * \\
(.298)\end{array}$ & $\begin{array}{l}.526 * * \\
(.226)\end{array}$ & $\begin{array}{l}.606 * * * \\
(.199)\end{array}$ & $\begin{array}{r}.691 \\
(2.82)\end{array}$ \\
\hline Motherhood interaction $^{a}$ & $\begin{array}{l}-2.14 * * * \\
(.651)\end{array}$ & $\begin{array}{c}-2.72 * * * \\
(.426)\end{array}$ & $\begin{array}{c}-2.38 * * * \\
(.548)\end{array}$ & $\begin{array}{c}-15.9 * * * \\
(2.42)\end{array}$ \\
\hline Intercept $\ldots \ldots \ldots \ldots \ldots \ldots \ldots$ & $\ldots .^{\mathrm{b}}$ & $\begin{array}{l}4.56 * * * \\
(.601)\end{array}$ & $\begin{array}{l}.210 \\
(.266)\end{array}$ & $\begin{array}{l}148 * * * \\
(2.55)\end{array}$ \\
\hline
\end{tabular}

NotE. - Robust SEs in parentheses; clustered by participant ID. $N=188$ participants. All values reported to three significant digits. See text for variable descriptions.

"Parent $\times$ female applicant.

Since ordered logistic regression produces multiple intercepts, we do not present them here

$* P<.10$

** $P<.05$

*** $P<.001$ 
women, parenthood has the opposite effect. Women without children were offered approximately $\$ 151,000$, whereas mothers were recommended a significantly lower salary of about $\$ 139,000$, or about $7.9 \%$ less than otherwise equal childless women. Compared to fathers, mothers were offered approximately $8.6 \%$ lower salaries.

Also of note in the salary model, African-American applicants were offered approximately $\$ 6,800$ lower salaries, on average, compared with those offered to whites. This difference is striking, especially since AfricanAmericans were not judged to be less competent or committed to workthey were simply offered lower salaries. The résumés in the AfricanAmerican conditions were exactly the same, except for first names, as those used in the white conditions, so differences in qualifications do not explain this finding. It appears that a different mechanism of discrimination is operating for African-Americans, or at least for applicants with distinctive African-American first names.

In sum, across all eight dependent variables, the motherhood penalty interaction is significant, and its sign is in the predicted direction. Given the strength of the effect across a diverse set of measures and the experimental control of applicant quality, we conclude that giving evidence of being a mother leads to discrimination against mothers. Being a father did not lead to similar disadvantages for men and, at times, actually led to advantages. We now turn to a brief discussion of a few additional research questions, starting with whether gender of participant impacts these results.

Does Participant Gender Impact the Size of the Motherhood Penalty?

Consistent with status characteristics theory, we expected both male and female participants to discriminate against mothers. Using our data to test this claim shows that even though female participants rated applicants higher overall on some measures, both female and male participants evaluated mothers significantly lower than nonmothers on all eight dependent variables. Only one significant difference was found in the magnitude of the motherhood penalty between male and female participants. In results not shown, we added the two-way interaction of participant gender and applicant gender and the three-way interaction of participant gender, applicant gender, and parental status to each of the models in tables 2, 3 , and 4. For models predicting how many days an applicant would be allowed to be late, the two-way interaction of participant gender and applicant gender was marginally significant and negative, and the threeway interaction of participant gender, applicant gender, and parent status was significant and positive. This means that female participants held all female applicants to a slightly harsher standard than male participants 
American Journal of Sociology

did, allowing female applicants fewer days of being late than male applicants, but they penalized mothers slightly less relative to childless women than male participants did. For all other dependent variables, the magnitude of the motherhood penalty did not differ significantly for male and female participants. We did not expect that the status-based discrimination mechanism would work differently for male and female participants, and the results are largely consistent with that prediction.

Do African-Americans and Whites Both Experience a Motherhood Penalty?

We predicted that both white and African-American mothers would experience a motherhood penalty compared with their same-race, childless counterparts. To evaluate this prediction and to compare the magnitude of the motherhood penalty for the two groups, we added the three-way interaction of applicant race, parental status, and applicant gender to each of the models described above (results not shown). The motherhood penalty interaction remains significant in each of the models when the three-way interaction is added, indicating that regardless of race, mothers experience negative biases in workplace evaluations. Further, the threeway interaction was significant in only one of the models. African-American mothers were rated as less likely to be promoted than white mothers, but none of the other three-way interactions were significant. Thus, data from the experiment suggest that African-American women and white women both experience a motherhood penalty, and the magnitude of that penalty is largely the same for both groups.

Do Competence and Commitment Ratings Mediate Workplace Evaluations?

Thus far, we have shown (1) that motherhood is a status characteristic (a trait with differentially valued states that impacts performance expectations) and (2) that motherhood disadvantages job applicants across diverse measures. To complete our argument, we need to give evidence that motherhood disadvantages job applicants because it is a status characteristic. To evaluate this argument, we added the competence and commitment measures as independent variables to the models predicting workplace evaluations (see table 5). According to the theory, employers have lower expectations for the workplace competence and commitment of mothers, and it is this lower expectation that leads them to discriminate against mothers in hiring, promotion, and salary decisions. If the theory is correct, then evaluations of competence and commitment should mediate the motherhood penalty. Not surprisingly, higher competence ratings 
TABLE 5

Estimated Regression Coefficients for the Mediation of Competence and Commitment on the Impact of Parental Status on Workplace Evaluations

\begin{tabular}{|c|c|c|c|c|}
\hline Independent Variables & $\begin{array}{l}\text { Promotion } \\
\text { Likelihood } \\
\text { (Ordered Logistic } \\
\text { Estimates) }\end{array}$ & $\begin{array}{c}\text { Management } \\
\text { Training } \\
\text { (Binary Logistic } \\
\text { Estimates) }\end{array}$ & $\begin{array}{c}\text { Hire? } \\
\text { (Binary Logistic } \\
\text { Estimates) }\end{array}$ & $\begin{array}{c}\text { Recommended Salary } \\
\text { in Thousands } \\
\text { of Dollars } \\
\text { (Linear Estimates) }\end{array}$ \\
\hline Competence......... & $\begin{array}{l}.628 * * \\
(.295)\end{array}$ & $\begin{array}{l}1.263 * * * \\
(.281)\end{array}$ & $\begin{array}{l}1.21 * * * \\
(.258)\end{array}$ & $\begin{array}{l}7.00 * * * \\
(1.99)\end{array}$ \\
\hline Commitment & $\begin{array}{l}.237 * * * \\
(.095)\end{array}$ & $\begin{array}{l}.206 * * \\
(.099)\end{array}$ & $\begin{array}{l}.308 * * * \\
(.081)\end{array}$ & $\begin{array}{l}1.08 \\
(.762)\end{array}$ \\
\hline Parent & $\begin{array}{l}.901 * \\
(.558)\end{array}$ & $\begin{array}{c}.508 \\
(.340)\end{array}$ & $\begin{array}{l}.433 \\
(.426)\end{array}$ & $\begin{array}{l}3.23 * \\
(1.78)\end{array}$ \\
\hline Female applicant & $\begin{array}{c}-.140 \\
(.426)\end{array}$ & $\begin{array}{l}.661 * * \\
(.332)\end{array}$ & $\begin{array}{l}.755 * \\
(.410)\end{array}$ & $\begin{array}{l}-.817 \\
(3.31)\end{array}$ \\
\hline African-American $\ldots \ldots \ldots \ldots \ldots \ldots \ldots$ & $\begin{array}{c}.374 \\
(.319)\end{array}$ & $\begin{array}{c}-.154 \\
(.237)\end{array}$ & $\begin{array}{c}-.092 \\
(.244)\end{array}$ & $\begin{array}{l}-6.30 * * * \\
(2.86)\end{array}$ \\
\hline Female participant & $\begin{array}{l}.557 * \\
(.316)\end{array}$ & $\begin{array}{l}.606 * * * \\
(.236)\end{array}$ & $\begin{array}{l}.755 * * * \\
(.254)\end{array}$ & $\begin{array}{r}.512 \\
(2.81)\end{array}$ \\
\hline Motherhood interaction ${ }^{\mathrm{a}}$ & $\begin{array}{c}-1.34 * * \\
(.646)\end{array}$ & $\begin{array}{c}-1.89 * * * \\
(.437)\end{array}$ & $\begin{array}{c}-1.39 * * \\
(.606)\end{array}$ & $\begin{array}{l}-8.52 * * * \\
(2.66)\end{array}$ \\
\hline Intercept $\ldots \ldots \ldots \ldots \ldots \ldots \ldots \ldots \ldots \ldots \ldots \ldots \ldots \ldots \ldots$ & $\ldots .^{b}$ & $\begin{array}{l}3.64 * * * \\
(.947)\end{array}$ & $\begin{array}{c}-2.09 * * * \\
(.702)\end{array}$ & $\begin{array}{l}140 * * * \\
(6.37)\end{array}$ \\
\hline Reduction of motherhood penalty (\%) & 37.4 & 30.5 & 41.6 & 46.4 \\
\hline
\end{tabular}

NotE. - Robust SEs in parentheses, clustered by participant ID. $N=188$ participants. All values reported to three significant digits. See text for variable descriptions. ${ }^{a}$ Parent $\times$ female applicant.

${ }^{\mathrm{b}}$ Since ordered logistic regression produces multiple intercepts, we do not present them here.

$* P<.10$.
$* * P<.05$

*** $P<.05$. 


\section{American Journal of Sociology}

lead to significantly higher recommended starting salaries, higher perceptions of applicant promotability, and increased odds of recommending the applicant for management and for hire. Similarly, higher commitment ratings were associated with significantly higher perceptions of applicant promotability and increased odds of recommending the applicant for management and for hire, although the impact of commitment rating on salary, while positive, was not significant.

More important, when the competence and commitment ratings were added to the models, the negative effect of motherhood status on workplace evaluations was significantly reduced.$^{13}$ As can be seen on the last row of table 5, the magnitude of the motherhood penalty was reduced by $46 \%$ in the salary model, by $31 \%$ in the recommend-for-management model, by $37 \%$ in the promotion likelihood model, and by $42 \%$ in the recommend-for-hire model. Consistent with theoretical predictions, competence and commitment do mediate, at least partially, the negative effect of motherhood status on workplace evaluations. In part, mothers are rated as less hirable, less suitable for promotion and management training, and deserving of lower salaries because they are believed to be less competent and less committed to paid work.

The negative effects of motherhood status were not completely eliminated when the competence and commitment measures were included in the models, however. Perhaps this is not surprising given the magnitude of the motherhood penalty in the original models. While we can only speculate on why this residual effect remains, it is possible that one or more additional discriminatory mechanisms are at work. For example, some evaluators may believe that mothers should not be in the workplace, but should instead be at home with their children. If so, they may view mothers as competent and committed to paid work, but still discriminate against them. That is, in addition to status-based discrimination, some evaluators may also engage in normative discrimination, in which they recognize the competence of mothers but believe that it is their duty to remain at home with their children. Future research that experimentally manipulates competence and commitment levels is needed to evaluate this alternative mechanism.

\footnotetext{
${ }^{13}$ To calculate whether the reductions in the magnitudes of the coefficients are significant, we follow the procedures for comparing regression coefficients between nested models as described by Clogg, Petkova, and Haritou (1995). We include both mediators in a single model because both are indicators that motherhood is a status characteristic, our theoretical mediating variable. Each mediator also reduces the motherhood penalty when included in the model separately (results available upon request).
} 
Motherhood Penalty

Do Actual Employers Discriminate against Mothers?

It is worth returning to the question of how the use of undergraduate students as evaluators impacts our findings. One concern with students is that, lacking workplace and hiring experience, they might be more likely to rely on stereotypes when making hiring decisions. If undergraduates are more likely to rely on stereotypes than employers, our study will overestimate the magnitude of the motherhood penalty. Conversely, because of their lack of workplace experience, students are less likely than people with more extensive experience to have had a "bad experience" with an employed mother and to generalize from this experience when evaluating other employees who are mothers. Further, to the extent that younger adults hold more egalitarian gender beliefs, they might be less likely than older adults to discriminate against mothers. Our study might thus underestimate the magnitude of the motherhood penalty. While the laboratory data are ideally suited to evaluate the mechanism of discrimination, they cannot establish the extent to which actual employers penalize mothers in the hiring process. To address this question, we turn to the audit study.

\section{THE AUDIT STUDY}

\section{Overview}

The audit methodology combines experimental design with real-life settings. As in laboratory experiments examining discrimination, audit studies isolate a characteristic of interest (e.g., race or gender) and test for discriminatory behavior. Distinct from most laboratory studies, audit study participants are the people who make important decisions about actual applicants, such as employers conducting new employee searches. While laboratory experiments occur in more highly controlled settings, thereby permitting closer investigation of the social and cognitive processes involved in an act of discrimination, audit studies provide greater generalizability of the results. Local and national organizations have conducted audits to measure discrimination based on gender and race in the housing and job markets since the establishment of the Fair Housing Act (Title VIII of the Civil Rights Act of 1968; Yinger 1986) and the Civil Rights Act of 1964 (Fix, Galster, and Struyk 1993; Pager 2003; Bertrand and Mullainathan 2003). The current study is the first to use the audit methodology to measure employment discrimination based on parental status.

To conduct this study, résumés and cover letters from a pair of fictitious, equally qualified, same-gender applicants (both female or both male) were 
American Journal of Sociology

sent to employers advertising for entry- and midlevel marketing and business job openings at a large, Northeastern city newspaper over an 18month period of time. Job openings were randomly assigned to either the male pair or female pair condition. As with the lab experiment, the samesex pair contained one parent and one nonparent, and parental status was counterbalanced across members of the pair. We monitored whether gender and parental status impact the odds that an employer will call back an applicant. Two additional features of the audit study design increase our ability to compare it to the laboratory experiment: (1) applicant résumés in the audit study were based on the templates used in the laboratory experiment, and (2) the actual jobs to which applications were sent were similar to the marketing position described in the laboratory experiment.

The design for this study was patterned after a recent audit study that examined the effect of race on employment decisions (Bertrand and Mullainathan 2003). The authors found that, depending on the race of the applicant, $5 \%-8 \%$ of their hypothetical applicants received a callback when applying for executive, management, and sales positions. Based on this callback rate and to ensure that we had sufficient statistical power to evaluate the effect of parental status, we submitted 1,276 résumés and cover letters to 638 employers over the 18 -month period following procedures described below.

\section{Procedure}

Each week all entry- and midlevel marketing and business jobs that matched our applicants' qualifications were selected from the Sunday edition of a newspaper in a large Northeastern city. On average, 13 job openings were selected per week, with a minimum of one job and a maximum of 39 jobs selected in one week over 18 months. We randomly assigned selected jobs to one of two conditions (male or female applicant pair), and then generated a pair of same-gender résumés and cover letters. Résumés were based on the same templates used in the laboratory experiment, presenting two applicants with uninterrupted work histories and equally strong educational credentials and professional experience. One member of the applicant pair was presented as a parent, as we describe below. Parental status was counterbalanced across the two versions of the application materials. Résumés and cover letters were submitted in the appropriate format, as requested by the employer in the job advertisement (i.e., e-mail, fax, or paper). Within each pair, applications were sent to employers one day apart, counterbalancing whether the parent or nonparent applied first. The purpose of this delay was to avoid 
raising undo suspicion by having our two sets of application materials arrive simultaneously.

Gender was manipulated by assigning female- and male-sounding first names to the résumés and cover letters. Since race did not impact the magnitude of the motherhood penalty in the laboratory experiment and because of the large number of applications already required to detect the effects of gender and parental status, race was not manipulated in the audit study. Instead applicants were given the same genderappropriate "white names" that were used in the laboratory experiment.

Parental status was manipulated on the résumé and on the cover letter. Consistent with the laboratory experiment, the résumé for the parent member of the applicant indicated that she or he was an officer in an elementary school parent-teacher association, while the nonparent member of the pair was presented as an officer in a college alumni association. In the laboratory experiment, we also manipulated parental status on a memo purportedly from the human resources department of the hiring company. Since we could not use this manipulation in the audit study, we instead manipulated parental status on the cover letter. The cover letter for the parent member of the applicant pair mentioned that she or he was relocating with his or her "family" to the city where the job was located. The cover letter for the nonparent member of the pair also mentioned that she or he was relocating to the hiring city, but did not mention a family.

We occasionally had to make slight adjustments to the application materials in order to satisfy conditions in the job advertisements. If salary requirements or histories were also requested, for example, a sentence was added to both cover letters stating that the applicant was flexible and prepared to discuss salary if interviewed for the position. If a job required fluency in a language other than English, this was added to both résumés. Of the 638 job advertisements, 83 (13.4\%) requested salary requirements or histories, and $34(5.3 \%)$ required fluency in a language other than English.

After applications were submitted, we monitored whether or not job candidates received a callback from potential employers by phone or email. Each hypothetical applicant had his/her own voice mail number and e-mail address, allowing us to track positive responses from employers. Any invitation to an interview on the phone or at a company office was considered a "callback." When an applicant received a callback, we responded nonobtrusively (by e-mail or leaving a message during nonwork hours) indicating that the applicant was no longer interested in the position. 
American Journal of Sociology

Results

Do real employers discriminate against mothers? We begin to answer this question by examining the proportions of applicants receiving a callback from employers by gender and parental status (shown in table 6). We compare this variable to the "would you hire this applicant" variable from the laboratory study (see table 1).

The results suggest that real employers do discriminate against mothers. In table 6 , we see that childless women received 2.1 times as many callbacks as equally qualified mothers $(6.6 \%$ compared with $3.1 \% ; P<.05)$. This finding is similar to the laboratory experiment (see table 1) in which childless women were recommended for hire 1.8 times more frequently than mothers. In the laboratory study, fathers were recommended for hire at a slightly higher rate, although the difference was only marginally significant. Likewise, in the audit study, fathers were called back at a higher rate, although the difference was not significant.

We now consider a multivariate model for the effects of parental status, applicant gender, and the interaction of parental status and applicant gender on the odds that an applicant receives a callback from an employer. Table 7 contains the estimated logistic regression coefficients and robust standard errors from the model. Standard errors are clustered by job ID to take into account the nonindependence of observations that result from sending a pair of applications for each job. As with the models from the laboratory experiment, we focus on the motherhood penalty interaction term, asking whether being a parent decreases the odds that a woman, but not a man, receives a callback.

As can be seen in table 7, the motherhood penalty interaction is significant and negative, while the main effect for parental status is insignificant, and the main effect for the female applicant variable is significant and positive. The significant negative motherhood penalty interaction term indicates that being a parent lowers the odds that a woman, but not a man, will receive a callback from employers. While we find no evidence of a fatherhood bonus in the audit study, as shown by the insignificant effect of parent status, the significant and positive main effect for the female applicant variable means that childless women are significantly more likely to receive a callback from employers compared with equally qualified childless men. These results are consistent with those found in the "Would you hire this applicant?" model in the laboratory experiment. Returning to the main result, the audit data show that mothers are disadvantaged when actual employers make hiring decisions. Furthermore, since the applicants being evaluated in this study were equally qualified by experimental design, we conclude that employer discrimination is responsible for the disadvantages we found. 
Motherhood Penalty

TABLE 6

Proportions of Applicants Receiving Callbacks by Gender and Parental

Status

\begin{tabular}{lcc}
\hline \hline & Callbacks/Total Jobs & Proportion Called Back \\
\hline Mothers $\ldots \ldots \ldots \ldots \ldots \ldots \ldots \ldots \ldots$ & $10 / 320$ & .0313 \\
Childless women $\ldots \ldots \ldots \ldots \ldots \ldots$ & $21 / 320$ & $.0656^{++}$ \\
Fathers $\ldots \ldots \ldots \ldots \ldots \ldots \ldots \ldots \ldots \ldots$ & $16 / 318$ & .0503 \\
Childless men $\ldots \ldots \ldots \ldots \ldots \ldots \ldots \ldots$ & $9 / 318$ & .0283 \\
\hline
\end{tabular}

Note. - Mothers and childless women applied to the same 320 jobs; fathers and childless men applied to the same 318 jobs. See text for variable descriptions.

${ }^{++} Z<.05$, test for difference in proportions between parents and nonparents.

Strengths and Limitations

The strength of the audit study is that it applies an experimental design in a real-world setting, allowing us to evaluate whether actual employers discriminate against mothers in the hiring process. While the laboratory study permits careful examination of the underlying mechanism of discrimination, the audit study allows us greater generalizability. The audit study does have a few limitations, however. Most notably, the dependent variable-whether an applicant is called back-is a crude measure for testing the status-based discrimination argument. Unlike the laboratory study, the audit study does not give us insight into the mechanism underlying discrimination, because it was not possible to collect employers' rankings of commitment, competence, performance standards, and other relevant variables. There is also far less control over the evaluation setting. That is, employers likely receive many more applications than those from the parent and childless pair that were part of the study, thereby introducing additional status information into the setting. These limits mean that while the audit study establishes that actual employers discriminate against mothers, it cannot establish why. Understanding the mechanism underlying discrimination is important if the goal is to find ways to reduce or eliminate the disadvantages mothers face.

By considering the results of these two companion studies simultaneously, however, we find support for the status-based discrimination mechanism using the laboratory data, and we see the real-world implications of the argument with data generated from the audit study. Further, these results are consistent with qualitative work showing that employers discriminate against mothers (Blair-Loy 2003; Crittenden 2001; Kennelly 1999) and with survey research that consistently finds a wage penalty for motherhood (Budig and England 2001; Anderson et al. 2003; Waldfogel and Meyer 2000). Thus, across a wide range of methodological approaches - each of which has its unique strengths and weaknesses-we 
American Journal of Sociology

TABLE 7

Estimated Binary Logistic Regression Coefficients for the Effects of Parental Status and Gender on the Odds of Receiving a Callback

\begin{tabular}{|c|c|c|}
\hline Independent Variable & Callback? & Robust SE \\
\hline Parent & .598 & .433 \\
\hline Female applicant & $.887 * *$ & .407 \\
\hline Motherhood interaction $^{\mathrm{a}} \ldots$ & $-1.38 * *$ & .590 \\
\hline Intercept $\ldots \ldots \ldots \ldots \ldots \ldots \ldots \ldots \ldots$ & $-3.54 * * *$ & .338 \\
\hline \multicolumn{3}{|c|}{$\begin{array}{l}\text { Note. }- \text { Clustered by job. Mothers and childless women applied to the same } 320 \text { jobs; } \\
\text { fathers and childless men applied to the same } 318 \text { jobs, for a total of } 1,276 \text { applications } \\
\text { to } 638 \text { jobs. All values reported to three significant digits. See text for variable descriptions. } \\
{ }^{\text {a }} \text { Parent } \times \text { female applicant. } \\
{ }^{*} P<.10 \text {. } \\
\text { ** } P<.05 \text {. } \\
\text { *** } P<.001 \text {. }\end{array}$} \\
\hline
\end{tabular}

find evidence that mothers experience disadvantages in workplace settings and that discrimination plays a role in producing these disadvantages.

\section{SUMMARY AND CONCLUSIONS}

In this project, we make two main contributions. First, we isolate and experimentally evaluate a status-based discrimination mechanism that is proposed to explain some of the disadvantages mothers experience in the paid labor market. While survey research has established that employed mothers experience a per-child wage penalty, net of the usual human capital and occupational factors that affect wages, this research has been unable to assess whether discrimination is in part responsible for this wage penalty.

The experiment presented here strongly supports the status-based discrimination mechanism. This is the first study to show consistent, significant evidence for the motherhood penalty over a broad range of measures. By experimentally holding constant the qualifications and background experiences of a pair of fictitious job applicants and varying only their parental status, we found that evaluators rated mothers as less competent and committed to paid work than nonmothers, and consequently, discriminated against mothers when making hiring and salary decisions. Consistent with our predictions, fathers experienced no such discrimination. In fact, fathers were advantaged over childless men in several ways, being seen as more committed to paid work and being offered higher starting salaries. The fact that evaluators offered higher salaries to fathers suggests that cultural beliefs about gendered labor markets and a family wage still shape the allocation of organizational rewards. One unexpected 
finding was that childless women were advantaged over childless men on several measures, including being seen as more competent and being more likely to be recommended for hire, although they were not offered significantly higher salaries. It is possible that evaluators perceive childless women as especially committed to paid work.

The second contribution we make in this project is to show that real employers discriminate against mothers. Ours is the first audit study to test for hiring discrimination on the basis of parental status, and therefore the first to provide causal evidence that mothers experience hiring discrimination. By using application materials adapted from the laboratory experiment to apply to over six hundred jobs, we found that prospective employers called mothers back about half as often as nonmothers. Fathers, by contrast, were not disadvantaged in the hiring process. In general, the findings of the audit study correspond closely to those from the laboratory study, providing converging evidence for the motherhood penalty across two studies employing different methods and samples.

While the data support the main hypothesis, the project has several limitations. First, the experiment only evaluated the status-based discrimination mechanism for a high-status job that appeared to require high levels of commitment. Whether mothers would experience the same type and amount of discrimination in lower-status jobs or in jobs that are more or less gender-typed is an open question. While we expect the motherhood penalty to apply to a wide range of jobs (as all jobs require some degree of competence and commitment), the magnitude of the effect likely varies with the job type. Existing survey analyses have found a motherhood penalty across a wide range of occupations and jobs. Additionally, one study has shown that the magnitude of the wage gap is actually largest for those who have only a high school-level education, suggesting that the penalty is not limited to high-status jobs (Anderson et al. 2003). Thus, although there is reason to suspect that the mechanism described here would apply in a wider range of jobs, experiments that vary the type of job are needed to evaluate this prediction.

Second, this study examines discrimination only at the point of hire. We predict that women who give evidence of being a mother would be held to a harsher standard and suffer decreased workplace evaluations at other junctures, such as when promotion decisions or decisions to award raises are made, but whether the mechanism holds at these other crucial junctures is also an empirical question. Finally, the study examines only one avenue for getting a job. It is possible that evaluators are more or less discriminating, for example, when candidates are recommended through social networks.

The results of this study have implications for understanding some of the enduring patterns of gender inequality in paid work. The motherhood 
American Journal of Sociology

penalty appears robust both internationally and historically. One analysis of income data found a motherhood penalty in Australia, Canada, the United Kingdom, the United States, Germany, Finland, and Sweden (Harkness and Waldfogel 1999). A more recent analysis (Misra, Budig, and Moller 2005) discovered a motherhood penalty in Austria, Germany, Italy, Luxembourg, the Netherlands, Canada, the United Kingdom, the United States, Belgium, France, and Sweden. Furthermore, the motherhood penalty appears to have remained stable over time (Avellar and Smock 2003). This study offers a partial explanation for the mechanism behind a widespread, durable phenomenon with implications for a broad segment of the population.

More generally, a gender gap in wages has persisted over the vast movement of women into paid labor in the United States since the early 1970s. While the magnitude of the gap decreased over much of this period (Charles and Grusky 2004; Blau and Kahn 2004), a sizeable gap remains, and the gap has not narrowed in recent years (Institute for Women's Policy Research 2006). As Glass (2004) notes, employed mothers are the group of women who account for most of this gap. While many factors are certainly responsible for its persistence, this study suggests that cultural beliefs about the tension between the motherhood and "ideal worker" roles may play a part in reproducing this pattern of inequality. A second enduring pattern of gender inequality is the so-called "glass ceiling," a metaphor for the barriers that restrict women's movement up the career ladder to the highest positions in organizations and firms. To the extent that employers view mothers as less committed to their jobs and less "promotable," the glass ceiling women face could be, in part, a motherhood ceiling.

Writing for the National Center for Policy Analysis, Denise Venable (2002) describes an analysis from the congressional budget office that found that among people ages 27 to 33 who have never had children, women's earnings approach $98 \%$ of men's. She concludes, "When women behave in the workplace as men do, the wage gap between them is small." Claims of unequal pay, she continues, "almost always involve comparing apples and oranges." However, since most employed men and employed women have children at some point in their lives, the most illustrative "within fruit" comparison is not the comparison of childless men to childless women, but the comparison of men with children to women with children. As the two studies reported here show, when women "behave as men do," giving evidence of being a parent, they are discriminated against, while their male counterparts are often advantaged by their parental status. Far from being an "apples to oranges" comparison, the male and female applicants who were evaluated in these studies were exactly 


\section{Motherhood Penalty}

equal by experimental design. That parental status disadvantaged only female applicants is strong evidence of discrimination.

\section{REFERENCES}

Acker, Joan. 1990. "Hierarchies, Jobs, and Bodies: A Theory of Gendered Organizations." Gender and Society 4:139-58.

Aigner, Dennis J., and Glen G. Cain. 1977. "Statistical Theories of Discrimination in Labor Markets." Industrial and Labor Relations Review 30:175-87.

Anderson, Deborah J., Melissa Binder, and Kate Krause. 2003. "The Motherhood Wage Penalty Revisited: Experience, Heterogeneity, Work Effort and Work-Schedule Flexibility." Industrial and Labor Relations Review 56:273-94.

Aronson, Elliot, Phoebe C. Ellsworth, J. Merril Carlsmith, and Marti Hope Gonzales. 1990. Methods of Research in Social Psychology. New York: McGraw-Hill.

Arrow, Kenneth J. 1973. "The Theory of Discrimination." Pp. 3-33 in Discrimination in Labor Markets, edited by O. Ashenfelter and A. Rees. Princeton, N.J.: Princeton University Press.

Avellar, Sarah, and Pamela Smock. 2003. "Has the Price of Motherhood Declined over Time? A Cross-Cohort Comparison of the Motherhood Wage Penalty." Journal of Marriage and the Family 65:597-607.

Becker, Gary S. 1985. "Human Capital, Effort and the Sexual Division of Labor." Journal of Labor Economics 3:S33-58.

Berger, Joseph, Bernard P. Cohen, and Morris Zelditch, Jr. 1966. "Status Characteristics and Expectation States." Pp. 29-46 in Sociological Theories in Progress, edited by Joseph Berger, Morris Zelditch, Jr., and Bo Anderson. New York: Houghton Mifflin.

. 1972. "Status Characteristics and Social Interaction." American Sociological Review 37:241-55.

Berger, Joseph, Hamit Fişek, Robert Norman, and Morris Zelditch, Jr. 1977. Status Characteristics and Social Interaction. New York: Elsevier.

Bertrand, Marianne, and Sendhil Mullainathan. 2003. "Are Emily and Greg More Employable Than Lakisha and Jamal? A Field Experiment on Labor Market Discrimination.” National Bureau of Economic Research Working Paper Series, no. 9873. Accessed September 2003. http://www.nber.org/papers/w9873.

Bielby, Denise D., and William T. Bielby. 1984. "Work Commitment, Sex-Role Attitudes, and Women's Employment." American Sociological Review 49:234-47.

Bielby, William, and James Baron. 1986. "Men and Women at Work: Sex Segregation and Statistical Discrimination." American Journal of Sociology 91:759-99.

Biernat, Monica, and Diane D. Kobrynowicz. 1997. "Gender and Race-Based Standards of Competence: Lower Minimum Standards but Higher Ability Standards for Devalued Groups." Journal of Personality and Social Psychology 72:544-57.

Blair-Loy, Mary. 2003. Competing Devotions: Career and Family among Women Executives. Cambridge, Mass.: Harvard University Press.

Blau, Francine D., and Lawrence M. Kahn. 2004. "The U.S. Gender Pay Gap in the 1990s: Slowing Convergence.” Working Paper no. 10853. National Bureau of Economic Research.

Budig, Michelle, and Paula England. 2001. "The Wage Penalty for Motherhood." American Sociological Review 66:204-25.

Charles, Maria, and David B. Grusky. 2004. Occupational Ghettos: The Worldwide Segregation of Women and Men. Stanford, Calif.: Stanford University Press.

Cleveland, Jeanette N. 1991. "Using Hypothetical and Actual Applicants in Assessing Person-Organization Fit: A Methodological Note.” Journal of Applied Social Psychology 21:1004-11.

Cleveland, Jeanette N., and Andrew H. Berman. 1987. "Age Perceptions of Jobs: 


\section{American Journal of Sociology}

Agreement between Samples of Students and Managers." Psychological Reports 61: 565-66.

Clogg, Clifford C., Eva Petkova, Adamantios Haritou. 1995. "Statistical Methods for Comparing Regression Coefficients between Models.” American Journal of Sociology 100:1261-93.

Cohen, Jacob. 1988. Statistical Power Analysis for the Behavioral Sciences. Hillsdale, N.J.: Erlbaum Associates.

Correll, Shelley J. 2001. "Gender and the Career Choice Process: The Role of Biased Self-Assessments." American Journal of Sociology 106:1691-1730.

- 2004. "Constraints into Preferences: Gender, Status and Emerging Career Aspirations." American Sociological Review 69:93-133.

Correll, Shelley J., and Stephen Benard. 2006. "Biased Estimators? Comparing Status and Statistical Theories of Gender Discrimination.” Pp. 89-116 in Social Psychology of the Workplace: Advances in Group Process, vol. 23. New York: Elsevier.

Correll, Shelley J., and Cecilia L. Ridgeway. 2003. "Expectation States Theory." Pp. 29-51 in Handbook of Social Psychology, edited by John Delamater. New York: Kluwer Academic Press.

Corse, Sara J. 1990. "Pregnant Managers and Their Subordinates: The Effects of Gender Expectations on Hierarchical Relationships." Journal of Applied Behavioral Science 26:25-48.

Crittenden, Ann. 2001. The Price of Motherhood: Why the Most Important Job in the World Is Still the Least Valued. New York: Metropolitan Books.

Cuddy, Amy J. C., Susan T. Fiske, and Peter Glick. 2004. "When Professionals Become Mothers, Warmth Doesn't Cut the Ice.” Journal of Social Issues 60:701-18.

Epstein, Cynthia, Carroll Seron, Bonnie Oglensky, and Robert Saute. 1999. The Part Time Paradox: Time Norms, Professional Lives, Family and Gender. New York: Routledge.

Fix, Michael, George C. Galster, and Raymond J. Struyk. 1993. "An Overview of Auditing for Discrimination." Pp. 1-68 in Clear and Convincing Evidence: Measurement of Discrimination in America, edited by Michael Fix and Raymond J. Struyk. Washington, D.C.: Urban Institute Press.

Foschi, Martha. 1989. "Status Characteristics, Standards and Attributions." Pp. 58-72 in Sociological Theories in Progress: New Formulations, edited by Joseph Berger, Morris Zelditch, Jr., and Bo Anderson. Boston: Houghton Mifflin.

. 1996. "Double Standards in the Evaluation of Men and Women." Social Psychology Quarterly 59:237-54.

Fuegen, Kathleen, Monica Biernat, Elizabeth Haines, and Kay Deaux. 2004. "Mothers and Fathers in the Workplace: How Gender and Parental Status Influence Judgments of Job-Related Competence." Journal of Social Issues 60:737-54.

Glass, Jennifer. 2004. "Blessing or Curse? Work-Family Policies and Mothers' Wage Growth over Time." Work and Occupations 31:367-94.

Halpert, Jane A., Midge L. Wilson, and Julia Hickman. 1993. "Pregnancy as a Source of Bias in Performance Appraisals." Journal of Organizational Behavior 14:649-63.

Harkness, Susan, and Jane Waldfogel. 1999. "The Family Gap in Pay: Evidence from Seven Industrialised Countries.” CASE paper 29: Centre for Analysis of Social Exclusion.

Hays, Sharon. 1996. The Cultural Contradictions of Motherhood. New Haven, Conn.: Yale University Press.

Heider, Fritz. 1958. The Psychology of Interpersonal Relations. New York: Wiley.

Hersch, Joni, and Leslie S. Stratton. 2000. "Household Specialization and the Male Marriage Wage Premium." Industrial and Labor Relations Review 54:78-94.

Hill, Martha. 1979. "The Wage Effects of Marital Status and Children." Journal of Human Resources 14:579-94.

Institute for Women's Policy Research. 2006. “The Gender Wage Ratio: Women's and 
Motherhood Penalty

Men's Earnings." http://www.iwpr.org/pdf/Updated2006_C350.pdf. Accessed February 17, 2007.

Kennelly, Ivy. 1999. "That Single Mother Element: How White Employers Typify Black Women." Gender and Society 13:168-92.

Kobrynowicz, Diane D., and Monica Biernat. 1997. "Decoding Subjective Evaluations: How Stereotypes Provide Shifting Standards." Journal of Experimental Social Psychology 33:579-601.

Korenman, Sanders, and David Neumark. 1991. "Does Marriage Really Make Men More Productive?" Journal of Human Resources 26:282-307.

Loh, Eng Seng. 1996. "Productivity and the Marriage Premium for White Males." Journal of Human Resources 31:566-89.

Lovaglia, Michael J., Jeffrey W. Lucas, Jeffrey A. Houser, Shane R. Thye, and Barry Markovsky. 1998. "Status Processes and Mental Ability Test Scores." American Journal of Sociology 104:195-228.

Misra, Joya, Michelle Budig, and Stephanie Moller. 2005. "Employment, Wages, and Poverty: Reconciliation Policies and Gender Equity." Paper presented at the annual meeting of the American Sociological Association, Philadelphia, August.

Monin, Benoît, and Dale T. Miller. 2001. "Moral Credentials and the Expression of Prejudice." Journal of Personality and Social Psychology 81:33-43.

Muthén, Linda K., and Bengt Muthén. 1998-2004. Mplus User's Guide, 3d ed. Los Angeles: Muthén and Muthén.

Oettinger, Gerald S. 1996 "Statistical Discrimination and the Early Career Evolution of the Black-White Wage Gap." Journal of Labor Economics 14:52-78.

Olian, Judy D., and Donald P. Schwab. 1988. "The Impact of Applicant Gender Compared to Qualifications on Hiring Recommendations: A Meta-analysis of Experimental Studies." Organizational Behavior and Human Decision Processes 41: 180-95.

Orloff, Ann. 1996. "Gender and the Welfare State." Annual Review of Sociology 22: $51-78$.

Pager, Devah. 2003. "The Mark of a Criminal Record.” American Journal of Sociology 108 (5): $937-75$

Phelps, Edmund S. 1972. "The Statistical Theory of Racism and Sexism." American Economic Review 62:659-61.

Ridgeway, Cecilia L. 2001. "Social Status and Group Structure." Pp. 352-75 in Blackwell Handbook of Social Psychology: Group Processes, edited by Michael A. Hogg and Scott Tindale. Malden, Mass.: Blackwell.

Ridgeway, Cecilia, and Shelley J. Correll. 2004. "Motherhood as a Status Characteristic." Journal of Social Issues 60:683-700.

Townsend, Nicholas W. 2002. The Package Deal: Marriage, Work and Fatherhood in Men's Lives. Philadelphia: Temple University Press.

Troyer, Lisa, and Lesley C. Younts. 1997. "Whose Expectations Matter? The Relative Power of First-Order and Second-Order Expectations in Determining Social Influence." American Journal of Sociology 103:692-732.

Venable, Denise. 2002. "The Wage Gap Myth." National Center for Policy Analysis, April 12. Brief Analysis no. 392. Accessed December 12, 2004. http://www.ncpa.org/ $\mathrm{pub} / \mathrm{ba} / \mathrm{ba392/.}$

Waldfogel, Jane, and Susan E. Meyer. 2000. "Gender Differences in the Low-Wage Labor Market." Pp. 193-232 in Finding Jobs: Work and Welfare Reform, edited by David Card and Rebecca Blank. New York: Russell Sage.

Webster, Murray, and Martha Foschi. 1988. "Overview of Status Generalization." Pp. 1-22 in Status Generalization: New Theory and Research, edited by Murray Webster and Martha Foschi. Stanford, Calif.: Stanford University.

Weeden, Kim A. 2005. "Is There a Flexiglass Ceiling? Flexible Work Arrangements and Wages in the United States." Social Science Research 34 (2): 454-82. 


\section{American Journal of Sociology}

Williams, Joan. 2001. Unbending Gender: Why Work and Family Conflict and What to Do about It. Oxford: Oxford University Press.

Yinger, John. 1986. "Measuring Discrimination with Fair Housing Audits: Caught in the Act." American Economic Review 76:881-93. 